\title{
Avaliação da qualidade interna de ovos em função da variação da temperatura de armazenamento
}

\author{
Quality interns eggs evaluation in function of the temperature \\ storage variation
}

Fabiana Bom Kraemer," Gisela Cornélia Hütten," Claudia Emília Teixeira," Henrique Silva Pardi," Sérgio Mano"

\begin{abstract}
Resumo
Com o objetivo de avaliar a alteração da qualidade interna de ovos armazenados sob refrigeração e à temperatura ambiente, analisaram-se 360 ovos brancos armazenados durante 18 dias. Metade das amostras manteve-se à temperatura de $4 \pm 1^{\circ} \mathrm{C}$, e a outra a $25 \pm 1^{\circ} \mathrm{C}$. Um total de 15 ovos, de cada tratamento, foi periodicamente avaliado para as variáveis: altura da câmara de ar, unidade Haugh (UH), índice da gema (IG), pH da clara e da gema, estabilidade da espuma e sólidos da clara e da gema. Quando comparados os dois tratamentos, os resultados para altura da câmara de ar, estabilidade da espuma, sólidos da clara e da gema e pH da clara e da gema, não mostraram variância significativa durante o período de armazenamento. Apesar de haver sido observada diferença significativa entre os dois tratamentos para as medidas de $\mathrm{UH}$ e IG, somente a UH mostrou-se confiável para a avaliação rotineira de qualidade dos ovos armazenados com e sem refrigeração. Finalmente, confirmou-se que o armazenamento à temperatura de refrigeração mantém por mais tempo a qualidade interna de ovos.
\end{abstract}

Palavras-chave: ovos, avaliação, qualidade interna.

\begin{abstract}
With an objective to evaluate alteration of the intern's quality of eggs stored under refrigeration temperature and to the ambient temperature, 360 white eggs were analyzed during 18 days. Half stayed to the temperature of $4 \pm 1^{\circ} \mathrm{C}$, and the other to $25 \pm 1^{\circ} \mathrm{C}$. Samples of 15 eggs of each treatment were periodically analyzed for the variables: air cell, Haugh unit (HU), yolk index (YI), egg white and yolk $\mathrm{pH}$, stability of egg white foams, egg white and yolk solids. When compared the two studied treatments, air cell, stability of egg white foams, egg white and yolk solids and egg white and yolk pH, the results didn't show any variance during the storage period. Although, it was observed significant differences on $\mathrm{HU}$ and $\mathrm{Yl}$, only HU evaluation was available for the routine analyze for internal quality of the eggs stored with and without refrigeration. Finally, it was confirmed that the refrigeration storage temperature extend time in the interns quality of eggs.
\end{abstract}

Keywords: eggs, evaluation, interns' quality.

\section{Introdução}

Em certas regiões da terra, as aves selvagens, terrestres e aquáticas, bem como os quelônios e sáurios, concorrem regular ou acidentalmente para a mesa do homem com saborosos e nutritivos pratos. Além destas, todas as espécies de aves domésticas fornecem ovos utilizáveis na alimentação humana. Entretanto, só o de galinha tem sido intensamente aperfeiçoado em todo o mundo, no sentido da grande produção de ovos, sendo nesse particular, a espécie de maior interesse econômico (Alves, 1946).

Diversos autores (Alves, 1946; Stadelman et al., 1988; Staldeman e Cotterill, 1977; Mulder, 1977; Krause e Mahan, 1991; Valle et al., 2000) afirmam que o ovo, em função de seu elevado conteúdo em proteínas, vitaminas e minerais, bem como por sua elevada digestibilidade, é reconhecido como um importante alimento para o ser humano. Podem, ainda, ser utilizados em outros produtos que não destinados ao consumo humano, como: ração para cães e gatos; experimentos (o albúmen é utilizado no laboratório como referência protéica quando comparado com outras fontes); fertilizantes; meios de cultura; na preparação de vacinas; proteínas purificadas; inseminação artificial; cosméticos e xampus; na arte e decoração.

Em todo o mundo são produzidos bilhões de ovos, ocorrendo intensa comercialização destes e seus produtos, e por serem susceptíveis às contaminações por microrganismos, inclusive por espécies patogênicas, são muito perecíveis. Por

\footnotetext{
* Programa de Pós-Graduação (Mestrado) em Medicina Veterinária da Faculdade de Veterinária da Universidade Federal Fluminense - UFF, área de concentração em Higiene Veterinária e Processamento Tecnológico de Produtos de Origem Animal.

** Departamento de Tecnologia dos Alimentos, Faculdade de Veterinária - Universidade Federal Fluminense - UFF - Rua Vital Brazil Filho, 64 CEP 24230-340 - Niterói, RJ - Brasil. E-mail: mtasbm@vm.uff.br
} 
isso, para se evitar alterações indesejáveis, com diminuição da qualidade, durante o transporte e armazenamento por longos periodos, faz-se necessário o uso de processos de conservação tais como: resfriamento, congelamento ou desidratação (Carvalho, 1991).

Porém, geralmente, quando o consumidor é questionado sobre aspectos de qualidade dos ovos de consumo, desconhece quais fatores deve considerar e, quase sempre, atémse a características externas, como tamanho, peso, cor, integridade da casca e uniformidade (Moraes, 1995). Contudo, tem-se tornado claro que o consumidor deve satisfazer-se com a aparência dos elementos internos do ovo, ou seja, com as medidas determinadas através das condições do albúmen e da gema. No Brasil, os estudos da degradação dos constituintes internos, assim como os fatores envolvidos na perda dessa qualidade, são escassos.

Sendo $95 \%$ do total da produção de ovos de galinhas no Brasil destinados ao consumo in natura (Alleoni, 1997), e tendo como principal método de conservação a refrigeração, esse estudo teve como objetivo avaliar a qualidade interna dos ovos de consumo em função das condições de armazenamento (tempo e temperatura).

\section{Material e métodos}

Foram utilizadas 30 dúzias de ovos brancos provenientes de aves do mesmo lote, da linhagem high sex com aproximadamente 10 meses de idade, colhidos logo após a postura e armazenados em colméias de papelão. Imediatamente, separaram-se os ovos em dois tratamentos: um mantido à temperatura de $4 \pm 1^{\circ} \mathrm{C}$ e outro a $25 \pm 1^{\circ} \mathrm{C}$, contendo cada um deles 180 ovos. Quinze ovos de cada tratamento foram periodicamente avaliados durante 18 dias.

Inicialmente foi determinado o peso dos ovos por meio de uma balança de precisão. Posteriormente, mediu-se a altura da câmara de ar com o. auxílio de um ovoscópio e um paquímetro. Seguiu-se a quebra dos ovos sobre uma superfície de vidro, sendo tomadas as seguintes medidas: altura da clara espessa e da gema, em milímetros, através de um micrômetro e os seus respectivos diâmetros com um paquímetro, também em milímetros. As claras foram separadas da gema, homogeneizadas, e imediatamente determinou-se $0 \mathrm{pH}$ de ambas, com auxílio de um phmetro Marca Horiba $\mathrm{M}-13$

Três subamostras de cada constituinte homogeneizado, contendo aproximadamente $10 \mathrm{~g}$, colocadas em cápsula de porcelana de peso conhecido, foram retiradas e os pesos totais anotados. As subamostras foram levadas à estufa a $105^{\circ} \mathrm{C}$ por 24 horas, sendo novamente pesadas. Pela diferença de peso foram calculadas as porcentagens de sólidos totais de cada componente (Moraes, 1995).

Mediu-se também a estabilidade da espuma através do método de Mckellar e Stadelman (1955) com algumas modificações. Em um recipiente plástico, foram colocados $100 \mathrm{~mL}$ proveniente da homogeneização de 15 claras, seguido de batedura por 60 segundos com multimixer Wallita, suficiente para a espuma atingir o ponto de neve. Em seguida transvasou-se a espuma para um funil de vidro e, com uma proveta, mediu-se a quantidade de liquido drenado após 30 minutos de repouso.
Os valores encontrados para o peso do ovo e para a espessura do albúmen denso foram aplicados na fórmula para 0 cálculo do escore da unidade Haugh (UH), segundo Silversides e Villeneuve (1994).

O índice da gema (IG) foi representado pela relação numérica entre a altura da gema e a média de seus diâmetros (Funk, 1948).

Os resultados obtidos foram estudados através da análise estatística descritiva simples, regressão linear e correlação de Pearson. Para a realização das referidas análises estatísticas e confecção dos gráficos utilizou-se o programa Microsoft Excel ${ }^{\circledR}$.

\section{Resultados e discussão}

Os resultados para unidade Haugh (UH), câmara de ar (CA), indice da gema (IG), volume drenado da espuma da clara, sólidos da clara e da gema, $\mathrm{pH}$ da clara e da gema podem ser visualizados nas Tabelas e Figuras $1,2,3,4,5,6,7$ e 8 , respectivamente.

A Figura 1 evidencia um decréscimo estatisticamente significante nos valores de $\mathrm{UH}$, de acordo com o aumento do tempo de armazenamento dos ovos para ambas as temperaturas $\left(1\right.$ e $\left.25^{\circ} \mathrm{C}\right)$, obedecendo à tendência normal confirmada por Williams (1992), a qual concorda com estudos realizados por Moraes (1995) e Alleoni (1997). Estas diminuições na UH tiveram uma correlação alta e significativa para os ovos armazenados tanto à temperatura ambiente $(r=0,98)$ como para os mantidos em refrigeração $(r=0,92)$. Estes dados, estão de acordo com o Programa de Controle da Qualidade dos Estados Unidos (EUA, 1972), que afirma que a partir do 3 ㅇ dia de armazenamento, à temperatura ambiente, a qualidade dos ovos decresce de valores $A A$, indicativos de excelente qualidade (superior a $72 \mathrm{UH}$ ) para valores $A$ (entre 55 e $72 \mathrm{UH}$ ). Em sete dias, para qualidade média $B$ (superior a 30) e em 17 dias para baixa qualidade (inferior a 30). À temperatura de refrigeração, o mesmo Programa comenta que a qualidade dos ovos inicia sua redução, a partir do 14 일 de armazenamento, dados estes similares aos do presente estudo. Este declínio, relevante à temperatura ambiente, possivelmente, resulta de processos fisiológicos intrínsecos no albúmen que acarretam um aumento na camada fluida.

Os dados relativos à câmara de ar podem ser observados na Figura 2, onde os valores médios aumentaram gradativamente com o passar do tempo de armazenamento, encontrando-se uma tendência de correlação positiva com a $U H_{\text {, }}$ demonstrando, assim, ser uma medida confiável da qualidade interna dos ovos. Entretanto, os valores da câmara de ar não demonstraram diferenças significativas entre as duas temperaturas estudadas, provavelmente por não haver um controle da umidade relativa do ambiente de armazena-mento, dificultando assim, a determinação da qualidade interna somente em função da altura da câmara de ar.

Todas as médias do IG (Figura 3) mostraram-se dentro dos limites de 0,30 a 0,50 (Tabela 3 ), quando armazenados à temperatura de $4^{\circ} \mathrm{C}$, limites estes considerados, por Romanoff e Romanoff (1963), normais para ovos frescos, enquanto à temperatura ambiente, a partir do $14^{\circ} \mathrm{dia}$, começou-se a observar valores inferiores a estes limites. Resultados semelhantes foram comentados por Staldelman e Cotterill (1977) e 
Tabela 1 - Valor médio de 15 ovos e desvio-padrão da unidade Haugh de ovos armazenados durante 18 dias a 4 e $25^{\circ} \mathrm{C}$

\begin{tabular}{ccccccccccccc}
\hline \hline & \multicolumn{10}{c}{ Temp. } & \multicolumn{10}{c}{} & $\mathbf{0}$ & $\mathbf{1}$ & $\mathbf{2}$ & $\mathbf{3}$ & $\mathbf{4}$ & $\mathbf{5}$ & $\mathbf{7}$ & $\mathbf{9}$ & $\mathbf{1 1}$ & $\mathbf{1 4}$ & $\mathbf{1 7}$ & $\mathbf{1 8}$ \\
\hline $\mathbf{4}$ & $89 \pm 7,5$ & $84 \pm 7,6$ & $82 \pm 8,1$ & $81 \pm 8,3$ & $79 \pm 7,3$ & $78 \pm 7,2$ & $78 \pm 8,2$ & $75 \pm 8,1$ & $75 \pm 10,0$ & $74 \pm 6,4$ & $66 \pm 7,6$ & $65 \pm 10,2$ \\
$\mathbf{2 5}$ & $89 \pm 7,5$ & $80 \pm 9,7$ & $75 \pm 9,7$ & $67 \pm 10,5$ & $66 \pm 9,5$ & $63 \pm 8,7$ & $51 \pm 7,9$ & $45 \pm 9,4$ & $45 \pm 8,9$ & $32 \pm 10,0$ & $19 \pm 7,9$ & $19 \pm 7,5$ \\
\hline
\end{tabular}

Temp. - Temperatura $\left({ }^{\circ} \mathrm{C}\right)$.

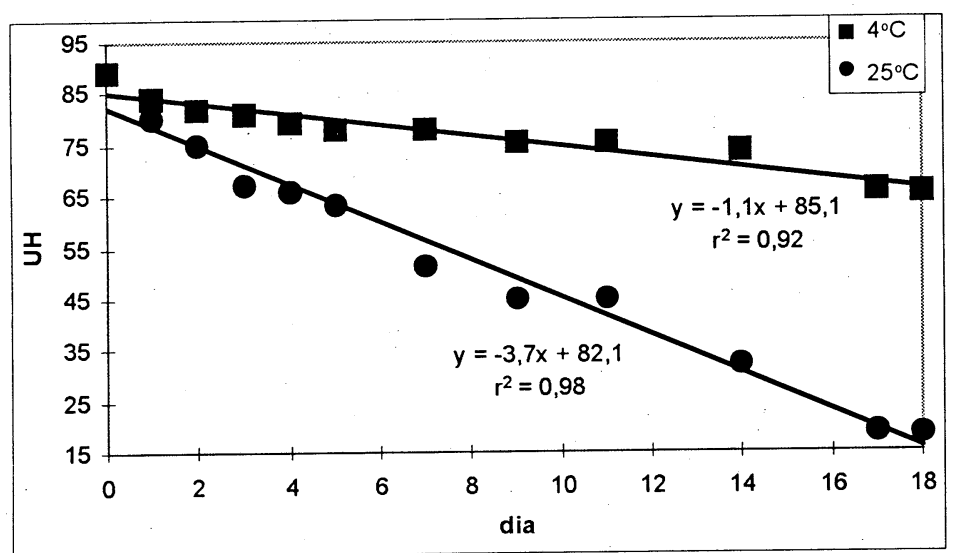

Figura 1 - Representação gráfica da média de 15 ovos, das unidades Haugh, suas linhas de tendência com respectivas equações e quadrado do coeficiente de correlação $\left(r^{2}\right)$ de ovos armazenados durante 18 dias a 4 e $25^{\circ} \mathrm{C}$
Staldelman et al. (1988), que podem ser explicados, provavelmente, em função do aumento da permeabilidade da membrana vitelínica em temperaturas elevadas, facilitando assim a migração de água presente no albúmem para a gema, devido à elevada pressão osmótica desta em função da maior quantidade de sólidos presentes. Portanto, como conseqüência deste aumento do teor de água na gema, ocorre a diminuição do IG. Porém, os autores citados anteriormente sugerem que, devido ao escape dos produtos da dissociação, os constituintes da desintegração molecular, como proteínas simples e ácidos graxos da gema, tendem a mover-se desta para o albúmen, a qual apresenta um aumento proporcional no seu teor de sólidos, enquanto na gema existe uma diminuição destes sólidos, comportamento este que pode ser associado aos resultados do presente trabaIho (Figura 7). Entretanto, discordando dos autores citados, não se observou, em nenhuma das temperaturas

Tabela 2 - Valor médio $(\mathrm{mm})$ de 15 ovos e desvio-padrão do tamanho da câmara de ar de ovos armazenados durante 18 dias a 4 e $25^{\circ} \mathrm{C}$

\begin{tabular}{|c|c|c|c|c|c|c|c|c|c|c|c|c|}
\hline \multirow{2}{*}{ Temp. } & \multicolumn{8}{|c|}{ Dia } & \\
\hline & 0 & 1 & 2 & 3 & 4 & 5 & 7 & 9 & 11 & 14 & 17 & 18 \\
\hline 4 & $2,4 \pm 0,5$ & $2,9 \pm 0,4$ & $3,1 \pm 0,5$ & $3,3 \pm 0,5$ & $3,5 \pm 0,5$ & $3,5 \pm 0,7$ & $3,9 \pm 0,6$ & $4,3 \pm 0,8$ & $4,8 \pm 0,6$ & $5,2 \pm 0,8$ & $5,3 \pm 0,5$ & $5,5 \pm 0,5$ \\
\hline 25 & $2,4 \pm 0,5$ & $2,8 \pm 0,6$ & $2,9 \pm 0,7$ & $3,3 \pm 0,8$ & $3,6 \pm 0,7$ & $3,9 \pm 0,7$ & $4,1 \pm 1,2$ & $4,5 \pm 0,8$ & $5,1 \pm 1,0$ & $5,9 \pm 0,3$ & $6,4 \pm 0,8$ & $6,4 \pm 1,1$ \\
\hline
\end{tabular}

Temp. - Temperatura $\left({ }^{\circ} \mathrm{C}\right)$.

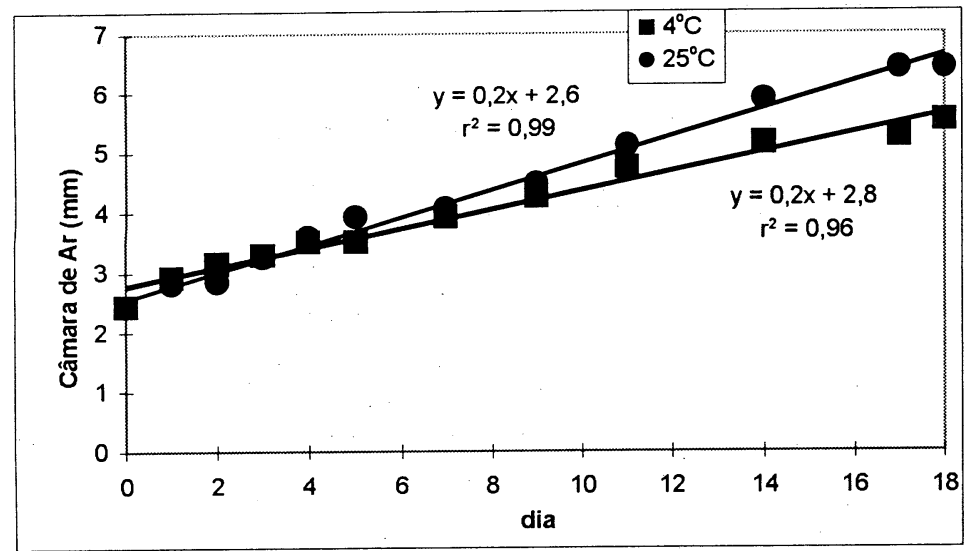

Figura 2 - Representação gráfica da média de 15 ovos, dos tamanhos das câmaras de ar, suas linhas de tendência com respectivas equaçōes e quadrado do coeficiente de correlação $\left(r^{2}\right)$ de ovos armazenados durante 18 dias a 4 e $25^{\circ} \mathrm{C}$ estudadas, o aummento de sólidos na clara (Figura 8), fato este que merece estudos mais aprofundados sobre a metodologia empregada no presente estudo.

Em relação ao pH da gema (Figura 4), apesar de observar-se um aumento gradativo deste, tanto a 4 como a $25^{\circ} \mathrm{C}$, tendendo a correlacionar-se negativamente com a UH (Figura 1), o mesmo não é expressivo para denotar uma perda de qualidade dos ovos, visto que, em 18 dias de armazenamento, somente se constatou uma variação máxima de 2 décimos da amostra mantida a $25^{\circ} \mathrm{C}$ (Tabela 4).

$\mathrm{O} \mathrm{pH}$ do albúmem de ovos frescos (Figura 5), foi o mais baixo em ambas as temperaturas de armazenamento, resultados similares àqueles encontrados na literatura, cujo valor varia de 7,6 a 8,3 (Powrie e Nakai, 1983; Alleoni, 1997). Tento na temperatura de refrigeração quanto na temperatura ambiente, houve um aumento de $\mathrm{pH}$ em relação aos ovos frescos, porém sem variação signifi- 
Tabela 3 - Valor médio $(\mathrm{mm})$ de 15 ovos e desvio-padrão do índice da gema de ovos armazenados durante 18 dias a 4 e $25^{\circ} \mathrm{C}$

\begin{tabular}{ccccccccccccc}
\hline \hline \multirow{2}{*}{ Temp. } & \multicolumn{10}{c}{$\mathbf{1 0}$ Dia } \\
\cline { 2 - 11 } & $\mathbf{0}$ & $\mathbf{1}$ & $\mathbf{2}$ & $\mathbf{3}$ & $\mathbf{4}$ & $\mathbf{5}$ & $\mathbf{7}$ & $\mathbf{9}$ & $\mathbf{1 1}$ & $\mathbf{1 4}$ & $\mathbf{1 7}$ & $\mathbf{1 8}$ \\
\hline $\mathbf{4}$ & 0,42 & 0,43 & 0,45 & 0,45 & 0,44 & 0,45 & 0,44 & 0,45 & 0,44 & 0,45 & 0,45 & 0,45 \\
$\mathbf{s d}$ & 0,02 & 0,02 & 0,02 & 0,04 & 0,03 & 0,03 & 0,03 & 0,03 & 0,02 & 0,03 & 0,07 & 0,02 \\
\hline $\mathbf{2 5}$ & 0,42 & 0,40 & 0,39 & 0,38 & 0,37 & 0,36 & 0,35 & 0,33 & 0,32 & 0,29 & 0,24 & 0,24 \\
sd & 0,02 & 0,02 & 0,03 & 0,03 & 0,03 & 0,04 & 0,03 & 0,02 & 0,03 & 0,05 & 0,02 & 0,04 \\
\hline \hline
\end{tabular}

Temp. - Temperatura $\left({ }^{\circ} \mathrm{C}\right)$, sd - Desvio-padrão.

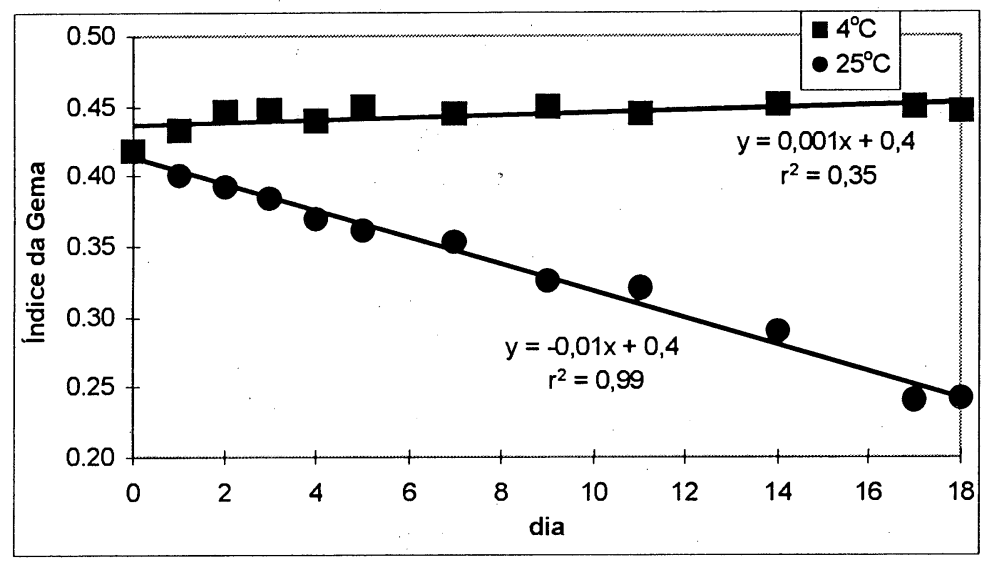

Figura 3 - Representação gráfica da média de 15 ovos, dos tamanhos índices da gema, suas linhas de tendência com respectivas equaçōes e quadrado do coeficiente de correlação $\left(r^{2}\right)$ de ovos armazenados durante 18 dias a 4 e $25^{\circ} \mathrm{C}$ cativa durante o período de armazenamento, confirmando, portanto, que as medidas de $\mathrm{pH}$ são utilizadas para descrever variações na qualidade do ovo após a estocagem, mas diferenças de pH não são associadas com diferenças de qualidade em ovos frescos (Silversides et al., 1993; Silversides e Villeneuve, 1994).

A estabilidade da espuma, avaliada através do volume $(\mathrm{mL})$ de líquido drenado da espuma (Figura 6), diminuiu em função do aumento do período de armazenamento independentemente da temperatura. Resultados estes, também obtidos por Alleoni (1997). A alteração dessa propriedade funcional se deve a uma diminuição na quantidade da proteína ovoalbumina, devido à sua conversão para s-ovoalbumina durante o período de armazenamento.

Tabela 4 - Valor de $\mathrm{pH}$, de 15 gemas de ovos armazenados durante 18 dias a 4 e $25^{\circ} \mathrm{C}$

\begin{tabular}{cccccccccccccc}
\hline \hline & \multicolumn{10}{c}{ Temp. } & \multicolumn{10}{c}{ Dia } \\
\cline { 2 - 13 } & $\mathbf{0}$ & $\mathbf{1}$ & $\mathbf{2}$ & $\mathbf{3}$ & $\mathbf{4}$ & $\mathbf{5}$ & $\mathbf{7}$ & $\mathbf{9}$ & $\mathbf{1 1}$ & $\mathbf{1 4}$ & $\mathbf{1 7}$ & $\mathbf{1 8}$ \\
\hline $\mathbf{4}$ & 5,44 & 5,44 & 5,46 & 5,47 & 5,47 & 5,49 & 5,50 & 5,52 & 5,53 & 5,54 & 5,55 & 5,55 \\
25 & 5,44 & 5,44 & 5,45 & 5,46 & 5,47 & 5,47 & 5,49 & 5,53 & 5,56 & 5,62 & 5,66 & 5,68 \\
\hline \hline
\end{tabular}

Temp. - Temperatura $\left({ }^{\circ} \mathrm{C}\right)$.

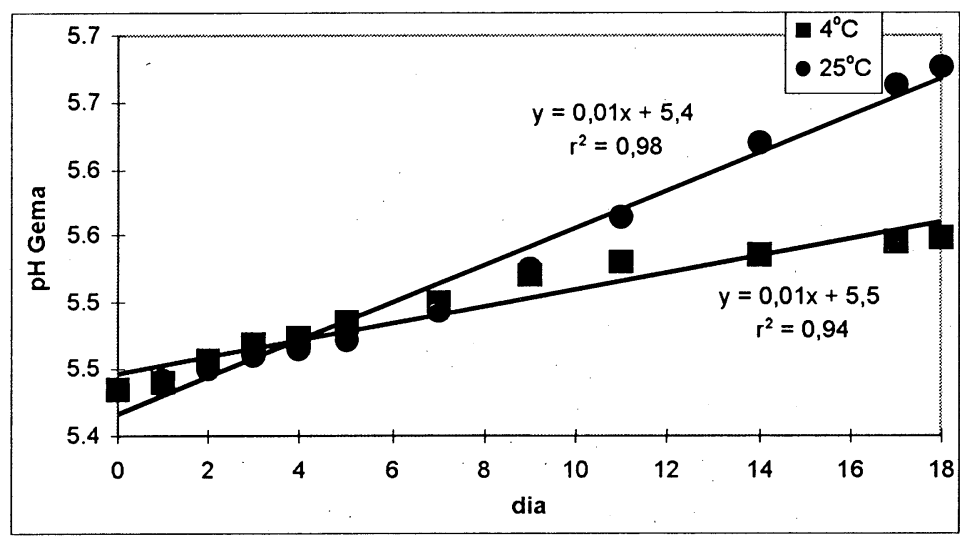

Figura 4 - Representação gráfica do valor de $\mathrm{pH}$, de 15 gemas de ovos armazenados durante 18 dias a 4 e $25^{\circ} \mathrm{C}$, suas linhas de tendência com respectivas equações e quadrado do coeficiente de correlação $\left(r^{2}\right)$ de ovos armazenados durante 18 dias a 1 e $25^{\circ} \mathrm{C}$ 
Tabela 5 - Valor de $\mathrm{pH}$, de 15 claras de ovos armazenados durante 18 dias a 4 e $25^{\circ} \mathrm{C}$

\begin{tabular}{|c|c|c|c|c|c|c|c|c|c|c|c|c|}
\hline \multirow{2}{*}{ Temp. } & \multicolumn{12}{|c|}{ Dia } \\
\hline & 0 & 1 & 2 & 3 & 4 & 5 & 7 & 9 & 11 & 14 & 17 & 18 \\
\hline 4 & 7,62 & 7,80 & 7,95 & 8,03 & 8,09 & 8,15 & 8,27 & 8,33 & 8,39 & 8,45 & 8,45 & 8,47 \\
\hline 25 & 7,62 & 7,98 & 8,15 & 8,30 & 8,39 & 8,51 & 8,69 & 8,76 & 8,75 & 8,75 & 8,74 & 8,75 \\
\hline
\end{tabular}

Temp. - Temperatura $\left({ }^{\circ} \mathrm{C}\right)$.

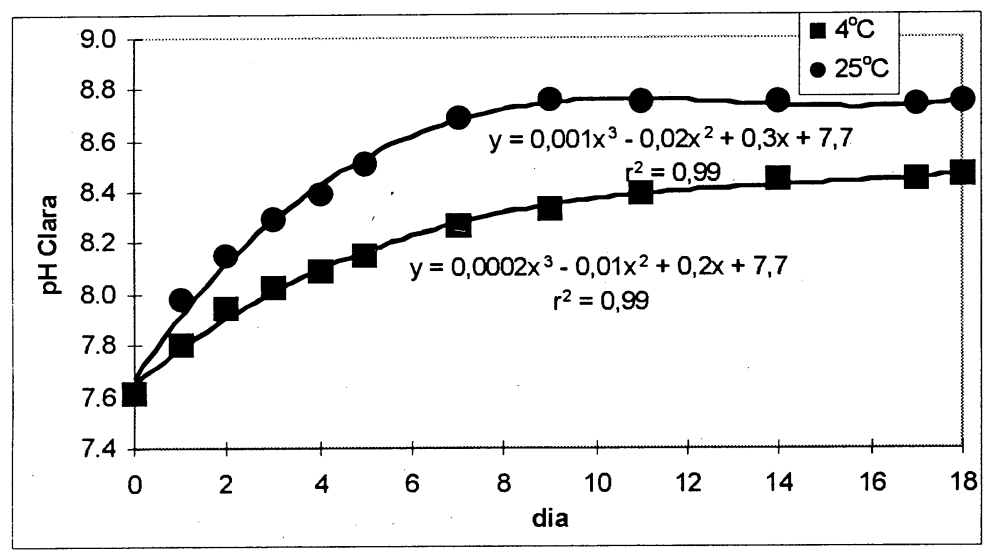

Figura 5 - Representação gráfica do valor de pH, de 15 claras de ovos armazenados durante 18 dias a 4 e $25^{\circ} \mathrm{C}$, suas linhas de tendência com respectivas equações e quadrado do coeficiente de correlação $\left(r^{2}\right)$ de ovos armazenados durante 18 dias a 1 e $25^{\circ} \mathrm{C}$

Tabela 6 - Líquido drenado da espuma (mL), de 15 claras de ovos armazenados durante 18 dias a 4 e $25^{\circ} \mathrm{C}$

\begin{tabular}{ccccccccccccc}
\hline & \multicolumn{10}{c}{ Temp. } & \multicolumn{10}{c}{ Dia } \\
\cline { 2 - 12 } & $\mathbf{0}$ & $\mathbf{1}$ & $\mathbf{2}$ & $\mathbf{3}$ & $\mathbf{4}$ & $\mathbf{5}$ & $\mathbf{7}$ & $\mathbf{9}$ & $\mathbf{1 1}$ & $\mathbf{1 4}$ & $\mathbf{1 7}$ & $\mathbf{1 8}$ \\
\hline $\mathbf{4}$ & 9,5 & 7,6 & 8,0 & 12,0 & 12,7 & 17,0 & 20,8 & 25,4 & 25,4 & 33,0 & 32,5 & 38,0 \\
$\mathbf{2 5}$ & 9,5 & 10,0 & 14,0 & 20,0 & 25,0 & 25,0 & 34,0 & 38,0 & 43,0 & 55,0 & 59,0 & 60,4 \\
\hline \hline
\end{tabular}

Temp. - Temperatura $\left({ }^{\circ} \mathrm{C}\right)$.

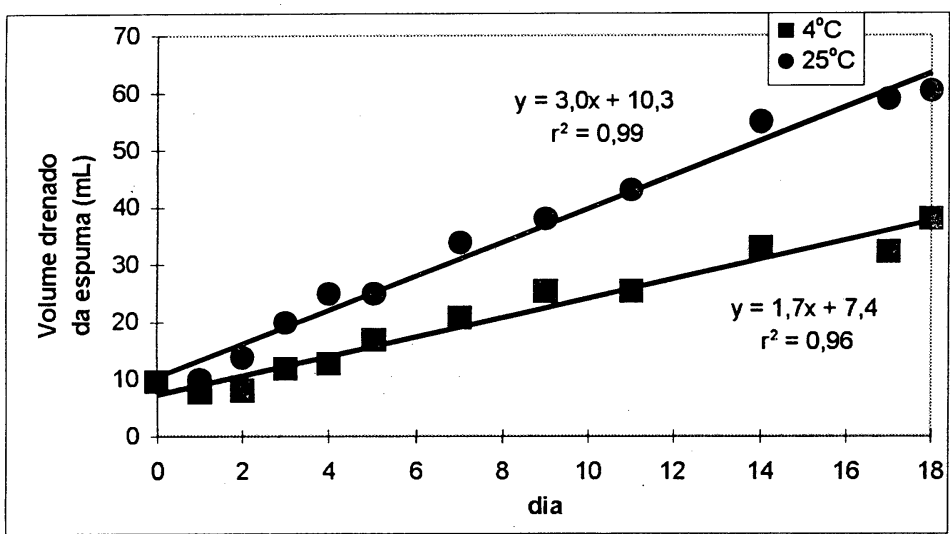

Figura 6 - Representação gráfica do líquido drenado da espuma $(\mathrm{mL})$, de 15 claras de ovos armazenados durante 18 dias a 4 e $25^{\circ} \mathrm{C}$, suas linhas de tendência com respectivas equações e quadrado do coeficiente de correlação $\left(r^{2}\right)$ de ovos armazenados durante 18 dias a 1 e $25^{\circ} \mathrm{C}$ 
Tabela 7 - Sólidos da gema (g), de 15 gemas de ovos armazenados durante 18 dias a 4 e $25^{\circ} \mathrm{C}$

\begin{tabular}{ccccccccccccc}
\hline & \multicolumn{1}{c}{} & \multicolumn{10}{c}{ Dia } \\
\cline { 2 - 13 } & $\mathbf{0}$ & $\mathbf{1}$ & $\mathbf{2}$ & $\mathbf{3}$ & $\mathbf{4}$ & $\mathbf{5}$ & $\mathbf{7}$ & $\mathbf{9}$ & $\mathbf{1 1}$ & $\mathbf{1 4}$ & $\mathbf{1 7}$ & $\mathbf{1 8}$ \\
\hline $\mathbf{4}$ & 50,10 & 47,94 & 50,53 & 45,83 & 48,90 & 48,37 & 49,71 & 48,28 & 45,00 & 43,49 & 50,11 & 47,94 \\
25 & 50,10 & 49,93 & 49,01 & 47,31 & 49,51 & 48,73 & 47,34 & 46,70 & 47,39 & 46,90 & 47,17 & 46,29 \\
\hline
\end{tabular}

Temp. - Temperatura $\left({ }^{\circ} \mathrm{C}\right)$.

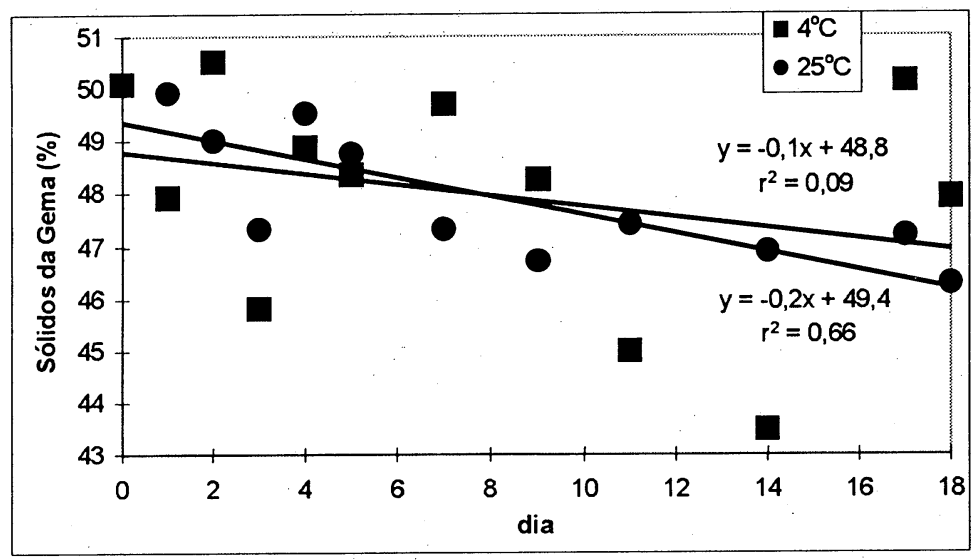

Figura 7 - Representação gráfica dos sólidos da gema (g), de 15 gemas, de ovos armazenados durante 18 dias a 1 e $25^{\circ} \mathrm{C}$, suas linhas de tendência com respectivas equações e quadrado do coeficiente de correlação $\left(r^{2}\right)$ de ovos armazenados durante 18 dias a 4 e $25^{\circ} \mathrm{C}$

Tabela 8 - Sólidos da clara (g), de 15 claras de ovos armazenados durante 18 dias a 4 e $25^{\circ} \mathrm{C}$

\begin{tabular}{|c|c|c|c|c|c|c|c|c|c|c|c|c|}
\hline \multirow{2}{*}{ Temp. } & \multicolumn{12}{|c|}{ Dia } \\
\hline & 0 & 1 & $\cdot 2$ & 3 & 4 & 5 & 7 & 9 & 11 & 14 & 17 & 18 \\
\hline 4 & 9,88 & 10,10 & 10,57 & 10,68 & 10,78 & 10,07 & 10,96 & 10,61 & 10,26 & 8,96 & 8,95 & 10,65 \\
\hline 25 & 9,88 & 10,23 & 9,94 & 11,65 & 9,71 & 9,63 & 10,51 & 11,20 & 10,44 & 10,39 & 10,41 & 11,69 \\
\hline
\end{tabular}

Temp. - Temperatura $\left({ }^{\circ} \mathrm{C}\right)$.

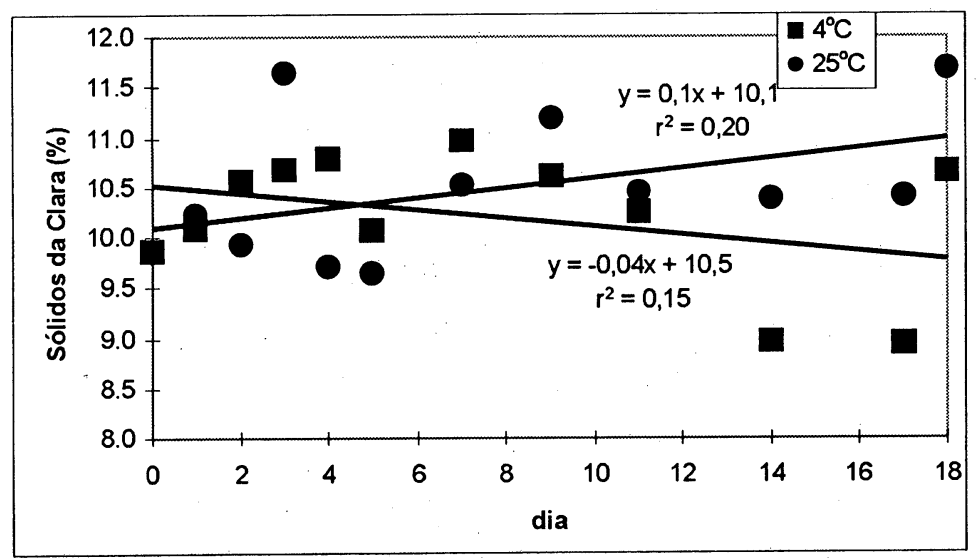

Figura 8 - Representação gráfica dos sólidos da clara (g), de 15 claras, de ovos armazenados durante 18 dias a 4 e $25^{\circ} \mathrm{C}$, suas linhas de tendência com respectivas equações e quadrado do coeficiente de correlação $\left(r^{2}\right)$ de ovos armazenados durante 18 dias a 1 e $25^{\circ} \mathrm{C}$ 


\section{Conclusões}

Baseado nos resultados obtidos, pode-se concluir que a altura da câmara de ar, estabilidade da espuma, sólidos da clara e da gema e $\mathrm{pH}$ da clara e da gema, nos dois tratamentos estudados, não variaram significativamente durante o período de armazenamento. Entretanto, observou-se um aumento progressivo das diferenças entre os resultados (entre 4 e $25^{\circ} \mathrm{C}$ ) obtidos para UH e IG. Portanto, o tamanho da câmara de ar não constituiu um parâmetro confiável para avaliação da qualidade dos ovos armazenados sob refrigeração quan-

\section{Referências}

ALLEONI,A.C.C. Efeito da temperatura e do período de ammazenamento na qualidade do ovo, nos teores de S-ovalbumina e nas propriedades funcionais das proteínas. Campinas: [s.n.], 1997. 110 p. Dissertação (Mestrado em Ciência da Nutrição) - Faculdade de Engenharia de Alimentos, Universidade de Campinas, 1997.

ALVES, N.G. O ovo de mercado. Rio de Janeiro: Ministério daAgricultura, Serviço de Documentação, 1946. 117 p.

CARVALHO, J.C.A.P. Análises microbiológicas do ovo desidratado padrão produzido no Brasil. Niterói: [s.n.], 1991. 184 p. Dissertação (Mestrado em Higiene Veterinária e Processamento Tecnológico de Produtos de OrigemAnimal) - Faculdade de Medicina Veterinária, Universidade Federal Fluminense, 1991.

EUA. United States Department of Agriculture (USDA). Egg Grading Manual, Agriculture Handbook no 75, Washington, 1972.

FUNK, E.M. The relation of the yolk index determined in natural position to the yolk index as determined after separating the yolk from the albumen. Poultry Science, v. 27, n. 3, p. 367, 1948.

KRAUSE, M.V.; MAHAN, L.K. Alimentos nutrição e dietoterapia: um livro-texto de cuidado nutricional. 7. ed. São Paulo: Roca, 1991, 981 p. MCKELLAR, M.B.; STADELMAN, W.J.A method for measuring volume and drainage of egg white foams. Poultry Science, v. 34, p. 455, 1955. MORAES, C.F.A. Qualidade interna de ovos comercializados em uma rede de distribuição em Uberlândia - MG. Belo Horizonte: [s.n.], 1995. do não existe um controle da umidade relativa, assim como o IG também não se mostrou viável para a avaliação de ovos mantidos à temperatura de refrigeração. A UH foi o parâmetro que melhor expressou a perda de qualidade interna dos ovos em ambas as temperaturas estudadas. No armazenamento à temperatura ambiente, a UH e o IG mostraram ser as medidas mais fidedignas, em se tratando de avaliação rotineira de qualidade dos ovos. $E$, finalmente, confirmou-se que 0 armazenamento à temperatura de refrigeração mantém por mais tempo a qualidade interna dos ovos.

Dissertação (Mestrado em Medicina Veterinária) - Escola de Veterinária, UFMG 1995.

MULDER, R.W. Safe poultry meat production in the next century. Acta. Vet. Hung., v. 43, p. 307-315, 1997.

POWRIE, W.D.; NAKAI, S. Características de los alimentos liquidos de origen animal: huevo. In: FENNEMA, O. Química de los alimentos. Zaragoza:Acribia, p. 931-959, 1983.

ROMANOFF, A.L.; ROMANOFF, A.J. The avian egg. 2. ed. New York: John Wiley \& Sons, 1963. $918 p$.

SILVERSIDES, F.G;TWIZEYMANA, F; VILLENEUVE, P. Research note: a study relating to the validity of the Haugh Unit correction for egg weight in fresh eggs. Poultry Science, v. 72, n. 4, p. 760-764, 1993.

SILVERSIDES, F.G; VILLENEUVE, P. Is the Unit Haugh correction for egg weight valid for eggs stored at room temperature? Poultry Science, v. 73, n. 1, p. $50-55,1994$.

STALDELMAN, W.J.; COTTERILL, O.J. Egg science \& technology. 2. ed. Wesrport: Avi Publishing Company, 1977.

STALDELMAN, W.J.; OLSON, V.M.; SHEMWELL, GA.; PASCH, S. Egg and poultry-meat processing. VCH Publishers, Ellis Horwood Ltda., Chichester (Inglaterra). 1988. 211 p.

VALLE, R.H.P.; BRESSAN, M.C.; CARVALHO, E.P. Tecnologia de ovos. Lavras: UFLAe FAEPE, 2000. $86 \mathrm{p}$.

WILLIAMS, K.C. Some factors affecting albumen quality with particular reference to Haugh Unit score. World's Poultry Science Journal, v. 48, n. 1 , p. $5-16,1992$. 